\title{
Integrated Renewable Energy Management System for Reduced Hydrogen Consumption using Fuel Cell
}

\author{
Vivekanadam B, \\ Professor, \\ Lincoln University, \\ Malaysia. \\ vivekanandam@lincoln.edu.my
}

\section{Dr. P. Karuppusamy,}

Professor, Department of EEE,

Shree Venkateshwara Hi-Tech Engineering College,

Erode, India.

Email id: pkarrupusamyphd@gmail.com

\begin{abstract}
The hybrid energy sources and their behavior may be controlled by monitoring and sensing with the help of a single or multiple control strategies incorporated in the energy management system. Utilization of the battery state of charge (SOC) and reduction in the consumption of hydrogen are the main objectives of battery and fuel cell (FC) based renewable hybrid power systems. The lifespan of the hydrogen storage as well as battery may be improved while improving the cost reduction benefits using these parameters. These objectives are achieved by designing an integrated energy management system (IEMS). A battery, supercapacitor (SC), proton-exchange membrane fuel cell (PEMFC) and Photovoltaic (PV) cell are combined to provide the required power to a predetermined load to form a renewable hybrid power system (RHPS). During daylight, PV is the master power source in RHPS. During the shading or night time, FC is the secondary power source. When high load power is required, the FC is supported by the battery. Load fast change or load transient operation is performed by the SC. Maximum SOC value and minimum hydrogen consumption value is obtained simultaneously based on predetermined functions that aids in switching between the state machine control, frequency decoupling and fuzzy logic based integrated strategies in the proposed energy management model. When compared to the stand-alone strategies, the integrated model achieves increased SOC and reduced hydrogen consumption. When maximum value of PV power is attained, the surplus power is displayed at the load. The battery
\end{abstract}


Journal of Electrical Engineering and Automation (EEA) (2021)

Vol.03/ No.01

Pages: $44-54$

https://www.irojournals.com/iroeea

DOI: https://doi.org/10.36548/jeea.2021.1.005

is charged using this surplus power. The stand-alone strategies and integrated strategy results are compared. The attainment of the goal of IEMS is confirmed from this comparison.

Keywords: Hydrogen consumption, Energy management strategy, Renewable energy, Supercapacitor, Photovoltaic, Fuel cell

\section{Introduction}

Hydrogen, wind, solar and other renewable energy sources are sought after due to the increasing energy demands caused by the rapid population growth [1]. The advantages of these resources towards the environment and humans is the reason for this dynamic shift. When compared to the conventional energy sources like natural gas, coal and heavy oil, the level of emission of carbon dioxide $\left(\mathrm{CO}_{2}\right)$ is lesser from the sustainable renewable sources [2]. Survey suggests a 40-110\% increase in $\mathrm{CO}_{2}$ by the year 2030. Reduction of $\mathrm{CO}_{2}$ emission and their harmful impact on air quality is the major goal. Increased $\mathrm{CO}_{2}$ emission may lead to increase in global temperature by $2^{\circ} \mathrm{C}$ annually [3]. This may be controlled with the use of renewable energy. Several billion dollars are invested in renewable energy over the past two decades. Power generation efficiency is high when multiple renewable energy sources are available in the energy systems [4]. Clean energy sources like hydrogen are largely analysed and their scope is evaluated by several researchers. Geothermal, wind, solar energy and other renewable sources as well as biofuel and biomass for the production of hydrogen are discussed. For the production of hydrogen and electricity using wind, solar and other renewable energy sources, the economic factors are also analyzed.

When compared to natural gas, renewable energy source based hydrogen used in fuel cells generate four times lesser greenhouse gases according to a study [5]. Electrolyzer is used for generation of hydrogen besides the external gird in renewable energy power system as discussed in various literature. In case, the system consists of surplus power, it is reinjected back to the grid when hydrogen fuel cell uses the generated hydrogen [6]. For obtaining electrical power from various renewable energy sources, hydrogen energy can be converted directly with the help of efficient energy conversion devices like proton-exchange membrane fuel cell (PEMFC). Longer life span, high energy, and high power are some of the benefits of 
lithium battery. In case of renewable energy storage, the best choice would be the use of LiIon battery when compared to other battery types [7]. Quick charging and discharging response, longer life cycle, high power density and environmentally friendly features are the benefits of energy storage elements like supercapacitors. In hybrid electrical power systems, energy storage may be performed efficiently by means of supercapacitor due to the aforementioned advantages.

\section{Literature Survey}

Supercapacitors, batteries and other energy storage devices consisting of fuel cells and hybrid energy systems are discussed by several literature [8]. A 3.7V lithium polymer battery system combined with maximum power point tracking system and stack configuration with 12 units of microbial fuel cell (MFC) is analyzed. Splitting the stack into four sub stacks increases the power extraction in the system by a factor of 8.5. An energy storage device or battery consisting of multiple renewable energy sources such as battery, wind or PV forms the integrated renewable power systems [9]. The climate condition affects these energy sources. Low wind speed, shading, night time and other climatic conditions significantly affects the power generated by the wind turbines and PV. The battery, FC and PV are combined together to form a hybrid renewable power system [10]. Dispersion via power sources can be performed through load power-sharing while applying several optimization techniques for enhancement. Perturb and observe (P\&O) as well as fuzzy logic control (FLC) approaches are used for optimization of PV arrays of maximum power point (MPP) [11]. During fast load change and transient operation, the supercapacitor would prove beneficial in this configuration. The battery source offers two-directional operation while FC and PV offers one directional operation while all sources make use of a single DC/DC converter. During the PV and load step change, steadystate and transient load operation at the proposed converter confirms its improved performance. However, system failure is a probable error that may occur in the system [12].

Several literature discusses similar configurations. The energy management system and multi-power system configuration enables stand-alone renewable energy power system based on DC to be used in hybrid electric vehicles (HEV) leading to lesser environmental impact and 
Journal of Electrical Engineering and Automation (EEA) (2021)

Vol.03/ No.01

Pages: $44-54$

https://www.irojournals.com/iroeea

DOI: https://doi.org/10.36548/jeea.2021.1.005

improved performance. FC/battery based hybrid system, SC/Battery/FC based hybrid power system, SC/FC based HEV system and their power configuration system along with energy management strategies has been discussed by several researchers [13]. The fast change and load transient offers quick system response advantages when battery/FC/PV systems are used as a secondary storage element along with supercapacitors. The internal electrochemical and thermodynamic response are slow curbing the efficiency of batteries and $\mathrm{FC}$ in responding to electrical load transients [14]. The SC/Battery/FC/PV based hybrid power system with load control and sharing is considered in certain literature. Based on the load power demand, successful coordination of power sources can be performed using these systems [15]. However, while charging the battery and supplying load, the hydrogen consumption factor has not been taken into consideration [16]. Single SC, single unit FC, multi stack batteries and multi PV panel based system and supercapacitor, battery FC and single PV based hybrid power system configurations are also analyzed. The renewable distributed generator (RDG) size optimization in supercapacitor, battery, FC and PV based hybrid power system are studied [17].

\section{Proposed Work}

The solar cell is represented by a single diode Photovoltaic (PV) module. Solar irradiance helps in generating the light source current in the solar cell. The movement of electrons in the PN junction diode built in the solar cell indicates the power generation. The PV module is modelled mathematically considering the internal parallel and series resistance. Supercapacitors and batteries are used as energy storage elements while FC and PVs are used as the integrated renewable energy power sources in the proposed microgrid architecture as shown in Figure 1. The charging and discharging process of the batteries are controlled by buck-boost and DC/DC converters. When there is a rapid change in the load, fast response is applied to the SC despite the unavailability of converters. Load fast change, surplus power and several other system conditions are considered for studying the system response while considering a random variable load. 


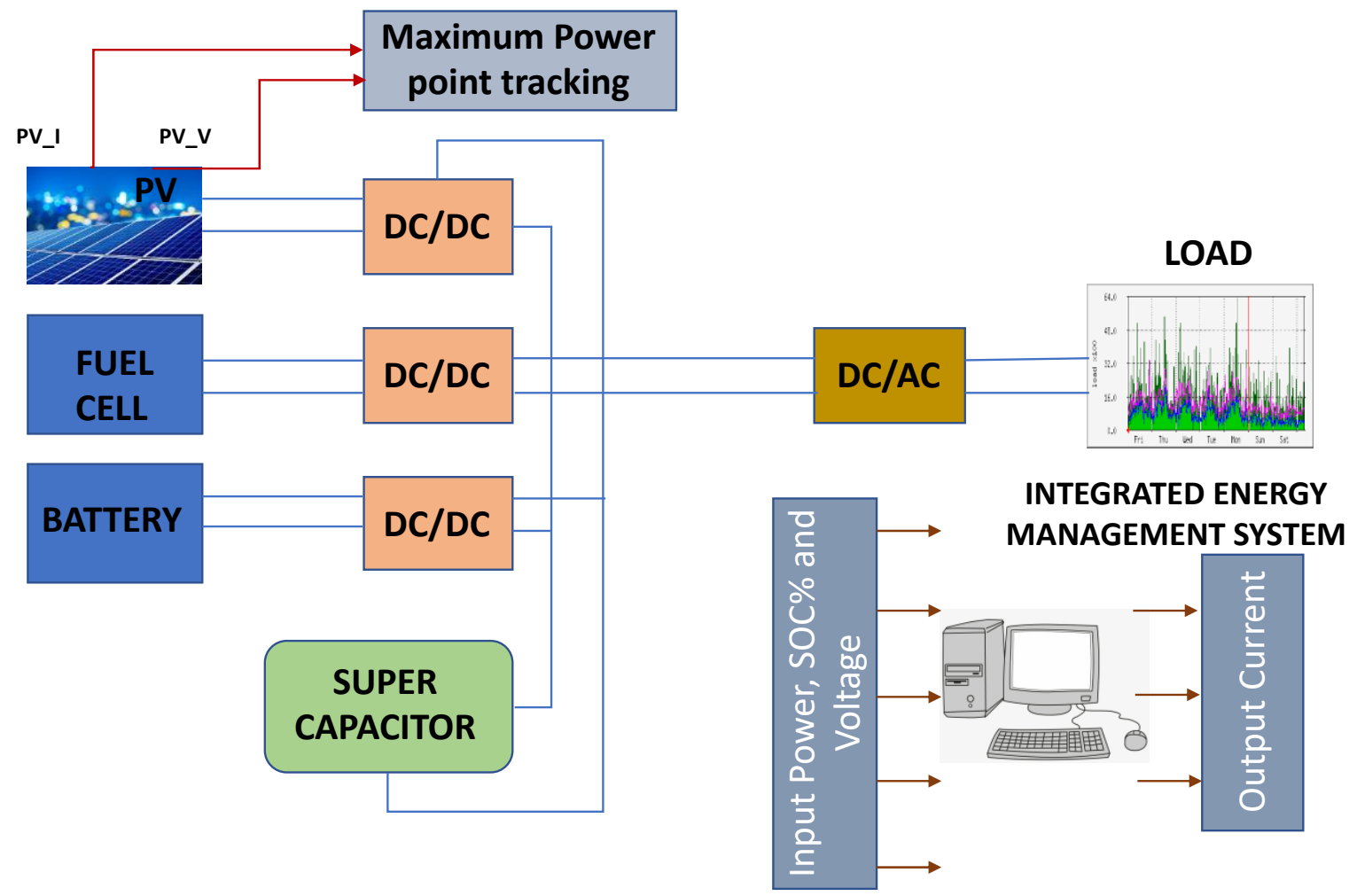

Fig. 1. Proposed integrated energy management architecture

MATLAB simulation is performed for PV panel modelling and other detailed modeling. The cell power, voltage and output current is calculated using mathematical modeling and representative equations. The equivalent circuit for each renewable power generation source is considered for calculation of the cell output current. Solar and wind energy systems are preferred due to the zero-emission. However, the high generation capacity of hydrogen from fuel cell makes it the most opted source. Due to the general and unique advantages of FC such as high energy density and low operating temperature, it is commonly used in hybrid systems like Proton Exchange Membrane fuel cell (PEMFC). The PEMFC offers emission free operation where only water is the by-product of the hydrogen and oxygen based electrochemical reactions that produce electricity using hydrogen as fuel. In electric vehicles, the PEMFC lifetime acts as a key parameter. Air, fuel flow rate, pressure, and temperature are the crucial parameters in fuel cell stack. Negative current is prevented from passing into the stack with the help of the diode and represented by the internal resistance of the stack. 
Journal of Electrical Engineering and Automation (EEA) (2021)

Vol.03/ No.01

Pages: $44-54$

https://www.irojournals.com/iroeea

DOI: https://doi.org/10.36548/jeea.2021.1.005

Lithium-Ion Batteries, sodium nickel chloride, Nickle eMetal Hydride Battery and Lead Acid Battery may be used for energy storage. Lithium-ion battery structure can be modified and improved to improve the accuracy of the model. The double layer diffusion and coulombs coefficient effects are also included for this purpose. The electrochemical and electromagnetic effects are represented by connecting two parallel branches in series. The ohmic resistance is represented by the internal resistance caused by connecting the DC voltage source in series forming the battery equivalent circuit. Degradation, useful life remaining and SOC\% are major parameters in lithium battery. Alarm, battery safety control, charge control and battery parameter detection are also prominent factors. The lithium battery is modelled mathematically and the representation of its equivalent circuit is obtained. The load current, long and short time capacitance and resistance, cell inductance, cell ohmic resistance and the open cell circuit are the functions used for representing the modified model of the equivalent circuit.

\section{Results and Discussion}

The simulation of the system is performed over a duration of 500 seconds. Zero irradiance value is observed with zero watts PV power and load power at the initial level of the simulation. Minimal power of the fuel cell is obtained and the battery is charged by the output power at the initial stage. Over $65 \%$ of the value of SOC\% is reached in 30 seconds. The slow response of battery and fuel cell and fast response of the supercapacitor in powering the load with supply causes an increase in the load power. The battery discharge current and fuel cell reference current may be used for powering the system by through the battery and fuel cell. The supercapacitor partially decreases the load power while battery and fuel cell are major factors in supplying the load power with decreased supercapacitor power. The battery power and fuel cell generated power decreases while power generation begins at the PV panel at 100 s simulation time. This load change attracts quick response from the supercapacitor. Based on the irradiance value, at highest power value of the PV panels, the load power reduces at 150 seconds. The battery may be charged again using the surplus power that exists in this scenario. The supercapacitor, battery and fuel cell decides the load power and the PV panel based power generation decreases with the decrease in irradiance value at 200 seconds. The power system performance over a duration of 500 seconds is represented in figure 2. During the simulation period, the power generation from multiple sources and load power is estimated. 
Journal of Electrical Engineering and Automation (EEA) (2021)

Vol.03/ No.01

Pages: 44-54

https://www.irojournals.com/iroeea

DOI: https://doi.org/10.36548/jeea.2021.1.005

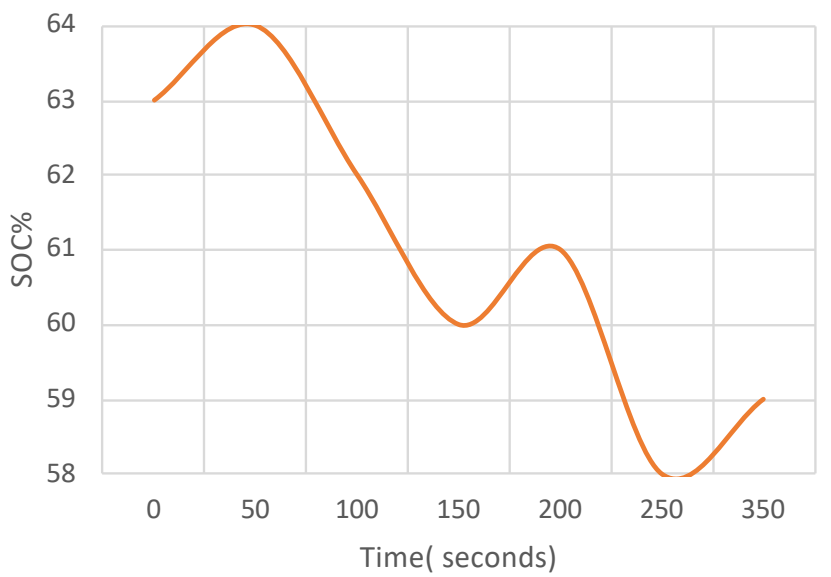

(a)

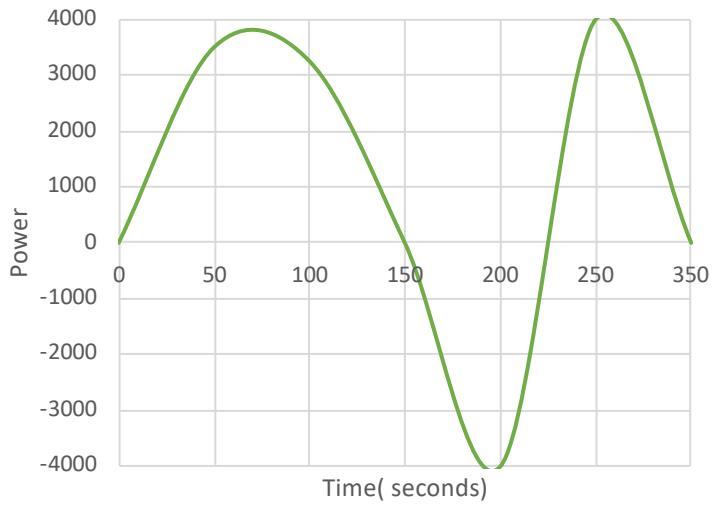

(b)

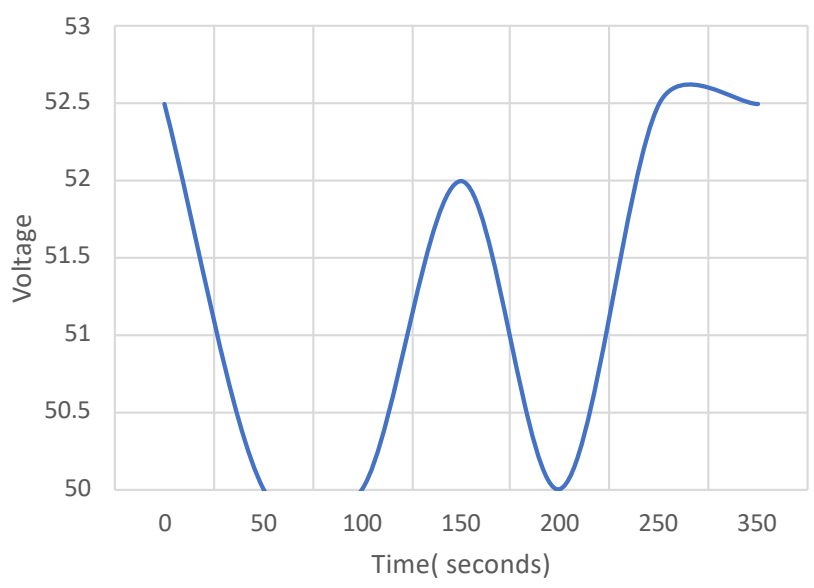

(c)

ISSN: 2582-3051 


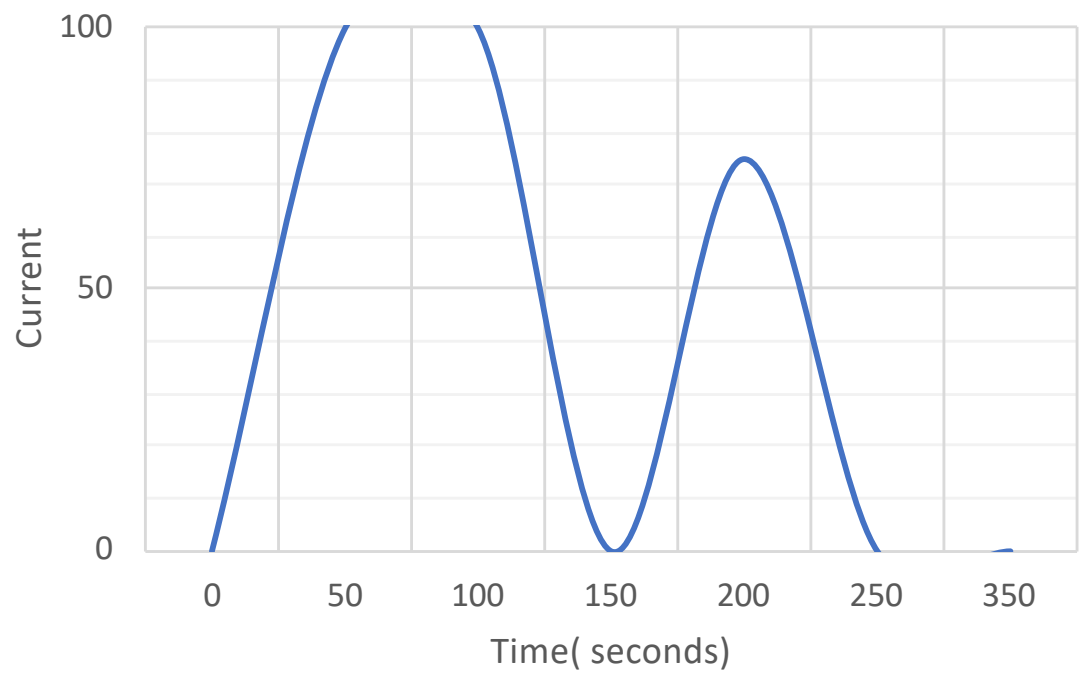

(d)

Fig. 2. Battery performance analysis in terms of (a) SOC, (b) power, (c) voltage, and (d) current

The difference between DC voltage and set point as well as PI controller output are used for determining the battery charging and discharging factors representing the battery performance. When the battery is charged by the fuel cell and zero load is available during the initial stage of the simulation, the battery SOC\% begins at $65 \%$. Within 300 seconds, the minimum power value is reached while supplying the load with required power through the power sources and discharging the battery while the load demand power is increased. The system encounters surplus power that is further used for charging the battery. At the end of simulation at the $500^{\text {th }}$ second, it is observed that there is an increase in the SOC\%. The battery output power is estimated as shown in figure 2 . With increasing load, the power supply to the system starts along with the charging procedure while representing the negative battery power during start-up. When the power generated by the PV are at the minimum value, maximum value is attained by the load with maximum power. Further, the battery voltage and current are also represented as s curves demonstrating the minimal discharging current at minimum output power when the battery faces maximum battery voltage. Maximum discharging current and battery output power is experienced with minimum battery voltage. 


\section{Conclusion}

The utilization of fossil fuels may be overcome by replacing the systems with renewable sources and integrated renewable power systems. Supercapacitors, lithium batteries and FCs that use hydrogen positively affects the climate change and greenhouse gas emission. While reducing the consumption of hydrogen in FC, in aircrafts and space, the hydrogen storage may be utilized while improving the optimization performance and lifespan reducing the cost in renewable integrated power systems with the proposed integrated energy management strategy. Durability, cost and other drawbacks of lithium batteries may be compensated partially by optimization of the battery state of charge percentage. For optimization of hydrogen storage, hydrogen may be produced using surplus power from the system. Future work is directed towards further optimizing the energy storage and management. When compared to the independent models, the integrated strategy offers improved performance and SOC\% values. Performance evaluation of modern optimization algorithms with the integrated energy management system is a possible future direction.

\section{References}

[1] Fathy, A., Yousri, D., Alanazi, T., \& Rezk, H. (2021). Minimum hydrogen consumption based control strategy of fuel cell/PV/battery/supercapacitor hybrid system using recent approach based parasitism-predation algorithm. Energy, 225, 120316.

[2] Kamel, A. A., Rezk, H., Shehata, N., \& Thomas, J. (2019). Energy management of a DC microgrid composed of photovoltaic/fuel cell/battery/supercapacitor systems. Electrochemical Capacitors, 29.

[3] Salameh, T., Abdelkareem, M. A., Olabi, A. G., Sayed, E. T., Al-Chaderchi, M., \& Rezk, H. (2021). Integrated standalone hybrid solar PV, fuel cell and diesel generator power system for battery or supercapacitor storage systems in Khorfakkan, United Arab Emirates. International Journal of Hydrogen Energy, 46(8), 6014-6027.

[4] Vivas, F. J., De las Heras, A., Segura, F., \& Andújar, J. M. (2018). A review of energy management strategies for renewable hybrid energy systems with hydrogen backup. Renewable and Sustainable Energy Reviews, 82, 126-155. 
Journal of Electrical Engineering and Automation (EEA) (2021)

Vol.03/ No.01

Pages: $44-54$

https://www.irojournals.com/iroeea

DOI: https://doi.org/10.36548/jeea.2021.1.005

[5] Aktaş, A., \& Kirçiçek, Y. (2020). A novel optimal energy management strategy for offshore wind/marine current/battery/ultracapacitor hybrid renewable energy system. Energy, 199, 117425.

[6] Bizon, N. (2019). Efficient fuel economy strategies for the Fuel Cell Hybrid Power Systems under variable renewable/load power profile. Applied Energy, 251, 113400.

[7] Hajiaghasi, S., Salemnia, A., \& Hamzeh, M. (2018, February). Hybrid energy storage performance improvement in microgrid application. In 2018 9th Annual Power Electronics, Drives Systems and Technologies Conference (PEDSTC) (pp. 392-397). IEEE.

[8] Ferahtia, S., Djeroui, A., Mesbahi, T., Houari, A., Zeghlache, S., Rezk, H., \& Paul, T. (2021). Optimal Adaptive Gain LQR-Based Energy Management Strategy for BatterySupercapacitor Hybrid Power System. Energies 2021, 14, 1660.

[9] Ferahtia, S., Djerioui, A., Zeghlache, S., \& Houari, A. (2020). A hybrid power system based on fuel cell, photovoltaic source and supercapacitor. SN Applied Sciences, 2(5), 1-11.

[10] Merad, F., Labar, H., Kelaiaia, M. S., Djelailia, O., \& Necaibia, S. (2020). Optimal fuel consumption planning and energy management strategy for a hybrid energy system with pumped storage. International Journal of Energy Technology and Policy, 16(5-6), 587-611.

[11] Li, S., Gu, C., Zhao, P., \& Cheng, S. (2021). Adaptive energy management for hybrid power system considering fuel economy and battery longevity. Energy Conversion and Management, 235, 114004.

[12] Nabipour, N., Qasem, S. N., \& Jermsittiparsert, K. (2020). Type-3 fuzzy voltage management in PV/Hydrogen fuel cell/battery hybrid systems. International Journal of Hydrogen Energy, 45(56), 32478-32492.

[13] Iqbal, M., Ramadan, H. S., \& Becherif, M. (2021). Health-aware frequency separation method for online energy management of fuel cell hybrid vehicle considering efficient urban utilization. International Journal of Hydrogen Energy, 46(29), 16030-16047.

[14] Yang, H., Li, Q., Wang, T., Qiu, Y., \& Chen, W. (2019). A dual mode distributed economic control for a fuel cell-photovoltaic-battery hybrid power generation system based on marginal cost. International Journal of Hydrogen Energy, 44(46), 25229-25239.

[15] Hengjinda, P., \& Chen, J. I. Z. Renewable Energy Production from Agricultural Waste and Hydrogen Battery Formation. 
Journal of Electrical Engineering and Automation (EEA) (2021)

Vol.03/ No.01

Pages: 44-54

https://www.irojournals.com/iroeea

DOI: https://doi.org/10.36548/jeea.2021.1.005

[16] Sakya, S. (2020). Design of Hybrid Energy Management System for Wireless Sensor Networks in Remote Areas. Journal of Electrical Engineering and Automation (EEA), 2(01), 13-24.

[17] Chen, J. I. Z., \& Lai, K. L. (2020). Machine Learning based Energy Management at Internet of Things Network Nodes. Journal: Journal of Trends in Computer Science and Smart Technology September, 2020(3), 127-133. 